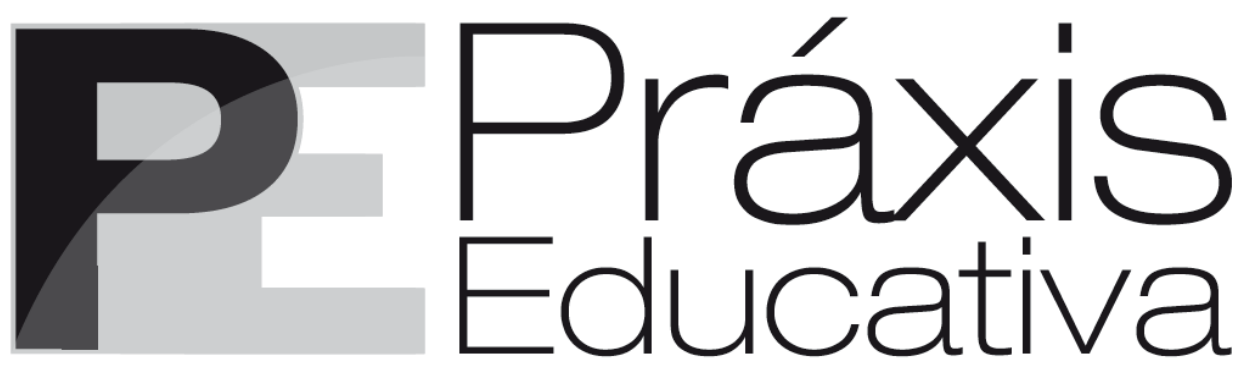

ISSN 1809-4031

elSSN 1809-4309

https://doi.org/10.5212/PraxEduc.v.15.14790.041

\title{
Unschooling: um estudo de caso sobre percursos de mediação cultural
}

\section{Unschooling: a case study on cultural mediation pathways}

\section{Unschooling: un estudio de caso sobre vías de mediación cultural}

Helen Rose Leite Rodrigues de Souza ${ }^{*}$

iD https://orcid.org/0000-0002-6451-7960

Carla Carvalho**

iD https://orcid.org/0000-0002-1402-7920

\begin{abstract}
Resumo: Este artigo, a partir de um estudo de caso, teve por objetivos: a) apresentar reflexões acerca do conceito de unschooling; b) descrever aspectos da prática do unschooling no cotidiano de uma família catarinense; e c) compreender percursos de mediação cultural, estéticos e artísticos, vivenciados por uma adolescente na prática do unschooling. Os dados analisados provieram de entrevistas com uma família catarinense praticante do unschooling, da análise do diário pessoal da adolescente integrante dessa família, além de estudos bibliográficos necessários à compreensão do conceito de unschooling e de dados registrados no Diário de Campo da pesquisadora. Diante dos dados gerados e da relação encontrada entre os termos "rede ou teia educacional", com Illich (1985), e "teia/rede de espaços educativos para a mediação cultural", com Kupiec, Neitzel e Carvalho (2016), teceu-se a formação de um novo conceito: "a teia/rede de mediação
\end{abstract} cultural no unschooling".

Palavras-chave: Experiência estética. Mediação cultural. Unschooling.

Abstract: This paper, based on a case study, aimed to: a) present reflections on the concept of unschooling; b) describe aspects of the unschooling practice in the daily life of a family from Santa Catarina, Brazil; and c) understand cultural, aesthetic and artistic mediation pathways experienced by an adolescent in the unschooling practice. The data analysed came from interviews with an unschooling practitioner family from Santa Catarina, from the analysis of the personal diary of the adolescent member of this family, as well as from bibliographic studies necessary to understand the concept of unschooling and data recorded in the field diary of the researcher. Given the data generated and the relationship found between the terms "educational network or web" with Illich (1985), and "Web/Network of educational spaces for cultural

\footnotetext{
* Professora de Artes da Rede Municipal de Ensino de Blumenau - SC. Mestre em Educação pela Universidade Regional de Blumenau (FURB). E-mail: <hrodrigues@furb.br>.

** Professora do Programa de Pós-Graduação em Educação da Universidade Regional de Blumenau (FURB). Doutora em Educação pela Universidade Federal do Paraná. E-mail: <carcarvalho@furb.br>.
} 
mediation" with Kupiec, Neitzel and Carvalho (2016), a new concept was formed: "the web/network of cultural mediation in unschooling".

Keywords: Aesthetic experience. Cultural mediation. Unschooling.

Resumen: Este artículo, a partir de un estudio de caso, tuvo como objetivos: a) presentar reflexiones sobre el concepto unschooling; b) describir aspectos de la práctica de unschooling en el cotidiano de una familia de Santa Catarina; y c) comprender las vías de mediación cultural, estéticas y artísticas, que fueron experimentadas por un adolescente en la práctica de unschooling. Los datos analizados provinieron de entrevistas con una familia de Santa Catarina practicante de unschooling, del análisis del diario personal de la adolescente integrante de esta familia, además de estudios bibliográficos necesarios para la comprensión del concepto de unschooling y de los datos registrados en el Diario de Campo de la investigadora. Delante de los datos generados y de la relación encontrada entre los términos "red o tela educativa", con Illich (1985), y "tela/red de espacios educativos para la mediación cultural", con Kupiec, Neitzel y Carvalho (2016), se tejió la formación de un nuevo concepto: "la red de mediación cultural en unschooling".

Palabras clave: Experiencia estética. Mediación cultural. Unschooling.

\section{Introdução}

O unschooling é um termo articulado à desescolarização, ${ }^{1}$ no sentido de tecer críticas ao sistema regular de ensino e propor maneiras outras de educar que rompem com elementos tradicionais presentes nas escolas. O unschooling liga-se ao homeschooling e a outras práticas que, embora adotem nomenclaturas diversas, têm como denominador comum o fato de acontecerem fora do sistema escolar (GONÇALVES, 2016). Nesse sentido, enquanto o "[...] homeschooling caracteriza uma forma de educar em casa, mantendo as técnicas e estratégias do sistema regular de ensino (currículo, material didático, formas de ensinar e aprender [...]" (GONÇALVES, 2016, p. 86), o unschooling toma uma direção contrária à vivência escolar, agindo de outro modo, fazendo diferente, a fim de criar outras possibilidades educativas (MONRAT, 2018).

Neste estudo, apresentaremos o unschooling como a prática e o caminho escolhido por uma família catarinense após a filha adolescente ter deixado a escola, no sexto ano do Ensino Fundamental. Segundo a família, sujeito deste estudo de caso, a escolha por essa prática educativa deu-se por dois fatores principais, quais sejam: a) em primeiro lugar, pela adaptação da família e, principalmente, da adolescente à estrutura imbricada com essa prática; b) em segundo lugar, por essa prática possuir um caráter de rompimento com as práticas realizadas no sistema regular escolar, quebrando, dessa forma, com o formato de educar presente na escola.

É importante esclarecermos que este estudo foi delineado em meio ao panorama de votações que permeou o Supremo Tribunal Federal (STF) em 2018 (BRASIL, 2018) e, em 2019, o Congresso Nacional; particularmente, neste último caso, com a tramitação do Projeto de Lei (PL) $\mathrm{n}^{\mathrm{o}} 2.401$, de 17 de abril de 2019, que prevê a regulamentação da educação domiciliar no Brasil (BRASIL, 2019).

Somadas a esse cenário de projetos e de votações, a maioria das produções científicas a respeito do tema podem ser consideradas recentes, pois teve início em 2013, conforme dados encontrados na Biblioteca Digital Brasileira de Teses e Dissertações (BDTD), no Catálogo de Teses

\footnotetext{
${ }^{1}$ Segundo Gonçalves (2016, p. 70): “O termo desescolarização tem ganhado força no Brasil e aparece entre práticas educacionais utilizadas como alternativas ao sistema regular de ensino, tais como o homeschooling e o unschooling”.
} 
e Dissertações da Coordenação de Aperfeiçoamento de Pessoal de Nível Superior (Capes) e na página da Associação Nacional de Educação Domiciliar².

Acrescidos a esses fatores, outros elementos justificam a realização do presente estudo, como a formação profissional das autoras em Artes Visuais, o vínculo deste estudo com uma pesquisa de Mestrado ligada ao campo da arte e da educação e a um Grupo de Pesquisa, cujo objetivo é investigar as relações entre arte, estética e educação, de modo a discutir as formas de interação dos sujeitos a partir de manifestações da arte, seja ela visual, cênica, musical ou literária. O intuito é compreender processos de mediação cultural e educação estética em espaços formais ou não formais de ensino. Portanto, tendo em vista essas questões e o contexto do unschooling no cotidiano da adolescente da família em tela, surgiram alguns questionamentos sobre a temática "percursos de mediação cultural estéticos e artísticos". Assim sendo, buscamos compreender quais percursos de mediação cultural estéticos e artísticos vivenciados pela adolescente na prática do unschooling. Assim, entendemos que "[...] o lugar que habitamos é responsável também por nossa formação estética e ele e seus objetos propositores também podem promover a mediação cultural" (KUPIEC; NEITZEL; CARVALHO, 2016, p. 25). Para isso,

[...] a arte é, aqui, percebida como o objeto de partida para o sentir e o construir. As pessoas e os espaços são os mediadores nesse processo de autonomia que se desencadeia, e uma grande teia de relações é construída mobilizando seres humanos em formação (KUPIEC; NEITZEL; CARVALHO, 2016, p. 28-29).

A mediação cultural é, portanto, compreendida como algo em constante percurso, que não se finda com as aulas, com as visitações aos espaços ou com as apresentações artísticas; ela se entrelaça às experiências do sujeito, interferindo no processo de aprendizagem (KUPIEC; NEITZEL; CARVALHO, 2016).

Na sequência, apresentamos o percurso metodológico desta pesquisa, alguns conceitos que nos ajudam a compreender o estudo e, por fim, os dados gerados e os resultados obtidos.

\section{Percursos metodológicos: um estudo de caso}

Este é um estudo de caso (FLICK, 2009) de abordagem qualitativa (BOGDAN; BIKLEN, 1994), pois tem como ponto de partida a observação detalhada de um sujeito, um acontecimento ou um contexto específico (BOGDAN; BIKLEN, 1994). Nesse caso, trata-se de "observação detalhada", cujo foco é compreender os percursos de mediação cultural no cotidiano de uma adolescente, no âmbito do processo de unschooling de uma família catarinense.

A escolha da família participante da investigação deu-se em função de uma das autoras ser professora na escola em que a adolescente estava matriculada antes de a família optar pela prática do unschooling. Diante do fato, nasceu o desejo de observar e compreender de perto, inicialmente,

\footnotetext{
${ }^{2}$ Em sua página, a ANED lista algumas produções científicas relacionadas à educação domiciliar. Em um breve levantamento entre as listadas, é possível perceber que se trata de trabalhos recentes, iniciados em 2014, com uma média de cinco trabalhos anuais até 2017, quando esse número cresceu para dezoito trabalhos publicados. Disponível em: <https://www.aned.org.br/conheca/trabalhos-academicos>. Acesso em: 20 mar. 2019. A respeito dos trabalhos científicos expostos na página da ANED e o processo de seleção para que eles sejam citados, sugere-se a reflexão acerca do perfil e o convir destes. Diante disso, recomendamos o artigo intitulado Os discursos da Associação Nacional de Educação Domiciliar do Brasil, de Casanova e Ferreira, publicado pela revista Práxis Educativa no ano de 2020, que põe em voga justamente o posicionamento da ANED em meio ao cenário de educação domiciliar a partir de seus discursos em sua página na internet e rede social, tornando-se influência ao movimento homeschooling em nosso país. Disponível em: <https://www.revistas2.uepg.br/index.php/praxiseducativa/article/view/14771/209209212855>. Acesso em: 30 mar. 2020.
} 
os motivos da escolha pelo unschooling e, depois, como a família faz as aproximações com os conceitos e as possibilidades próprios ao campo da arte.

Após obter a autorização da família, por meio do Termo de Consentimento Livre e Esclarecido (TCLE), e de um Parecer favorável ( $n^{\circ}$ 3.214.500), por parte do Comitê de Ética, realizamos o acompanhamento do cotidiano da adolescente, com o intuito de analisar seu Diário Pessoal, compartilhado conosco de maneira digital, e realizar entrevista semiestruturada com os pais e a adolescente durante uma das visitas à casa da família. Por questões éticas e de privacidade, os pais e a adolescente terão seus nomes resguardados e serão identificados pelos seguintes acrônimos: mãe da adolescente (M), pai da adolescente (P) e adolescente (A).

O Diário da adolescente foi o documento solicitado para a pesquisa (FLICK, 2009), e, dele, servimo-nos como instrumento para investigar os percursos de mediação cultural trilhados por sua autora. Segundo Bogdan e Biklen (1994), a análise de documentos requer atenção, pois são ricas fontes de dados. Para Flick (2009), os documentos são elementos que possibilitam interpretar o caso específico de uma história de vida ou de um processo.

A entrevista, neste caso, serviu como a porta de entrada que nos possibilitou compreender e mapear o mundo dos sujeitos (GASKELL, 2002), pois forneceu dados básicos para o desenvolvimento e a compreensão da situação e das relações havidas entre os atores sociais em estudo. Outra justificativa para o uso de entrevistas, neste estudo de caso, deu-se em função do desenho da pesquisa, pois investigamos a família. Nesse contexto,

[...] os indivíduos que partilham uma característica particular, mas que não formam grupos, podem ser sujeitos de um estudo qualitativo, mas, regra geral, a entrevista representa, neste caso, uma melhor forma de abordagem do que a observação participante. Aquilo que partilham entre si revelar-se-á mais claramente quando solicitar, individualmente, as suas perspectivas, e não enquanto observa as suas atividades. (BOGDAN; BIKLEN, 1994, p. 92).

Em função disso, a entrevista foi uma das opções de instrumentos para investigarmos essa família, haja vista ela possuir uma característica ímpar na prática do unschooling, pois não há regra nem uniformidade para essa prática, de tal sorte que outras famílias podem agir de maneira diferente. Assim sendo, não há o intuito de generalizar o percurso dessa prática, estendendo-o às demais famílias brasileiras que também compartilham dos mesmos ideais de unschooling. Embora tenhamos entrevistado três participantes, as entrevistas foram realizadas de maneira individual, tendo em vista que esta pesquisa fez uso da pesquisa individual de profundidade (GASKELL, 2002).

Por considerarmos a fase da interpretação dos dados tão importante quanto outras fases da pesquisa (MARCONDES; BRISOLA, 2014), indicamos que os dados gerados foram analisados por meio da triangulação de métodos. "A triangulação é uma ferramenta útil ao pesquisador sobretudo qualitativo - que deseja aumentar a confiabilidade dos resultados de sua pesquisa e de suas conclusões" (ZAPPELLINI; FEUERSCHÜTTE, 2015, p. 268).

A análise por triangulação de métodos foi sistematizada inicialmente na preparação do material gerado e, posteriormente, na articulação entre três aspectos, para então se proceder à análise (MARCONDES; BRISOLA, 2014).

O primeiro aspecto se refere às informações concretas levantadas com a pesquisa, quais sejam, os dados empíricos, as narrativas dos entrevistados; o segundo aspecto compreende o diálogo com os autores que estudam a temática em questão; e o terceiro aspecto se refere à análise de conjuntura, entendendo conjuntura como o contexto mais amplo e mais abstrato da realidade. (MARCONDES; BRISOLA, 2014, p. 204).

Práxis Educativa, Ponta Grossa, v. 15, e2014790, p. 1-19, 2020

Disponível em: <https://www.revistas2.uepg.br/index.php/praxiseducativa> 
A articulação entre esses três aspectos: dados empíricos, autores que tratam da temática estudada e análise de conjuntura, apresenta-se como uma entre tantas possibilidades de aproximar fundamentação teórica e prática de pesquisa (MARCONDES; BRISOLA, 2014).

Esclarecidos esses pontos, apresentaremos, em seguida, conceitos relacionados ao unschooling e mediação cultural e, na sequência, a partir dos dados gerados, duas categorias para subsidiar a compreensão dos percursos de mediação cultural percorridos pela adolescente no unschooling, a saber: i) os aspectos da prática do unschooling no cotidiano da família investigada; e ii) teia de relações: unschooling e os percursos de mediação cultural e sua aproximação com a arte.

\title{
Unschooling, conceitos relacionados e mediação cultural
}

Em nosso país, existem diversas práticas educacionais alternativas ao sistema tradicional de ensino, nomeadas homeschooling ou educação domiciliar, mas se trata de práticas distintas (MONRAT, 2018). Em função disso, neste artigo, optamos pelo termo "educação fora da escola" (LORETI, 2019), de maneira ampla, como alternativa ao termo "educação domiciliar", recorrente nos debates jurídicos, acadêmicos e midiáticos, que é constante e exclusivamente atrelado à prática do homeschooling.

Segundo dados da ANED (2019), cerca de 7,5 mil famílias brasileiras praticam atualmente a educação domiciliar, o que corresponde a 15 mil estudantes entre 4 e 17 anos, aproximadamente. Contudo, os dados apresentados pela ANED não classificam ou individualizam quais práticas de educação domiciliar foram incluídas na pesquisa realizada.

Assim, compreender qual o conceito subjacente ao termo "unschooling” a que os sujeitos deste estudo se referem como prática educacional, além de ser um dos objetivos do campo da educação, é também fonte de indagações. Em primeiro lugar, na tentativa de traduzir literalmente o termo do inglês para o português, buscamos auxílio em dicionários on-line, porém nenhum dicionário de língua portuguesa apresentou traduções do termo em nosso idioma. Procuramos, então, a compreensão e a origem do termo nos referenciais teóricos específicos, como Farenga (2013a) e Monrat (2018), bem como em pesquisas correlatas, de autoras como Gonçalves (2016) e Salgado (2018).

Utilizamos, neste estudo, o conceito formulado por Gonçalves (2016), por apresentar de maneira mais clara e direta as características da prática. De acordo com a autora:

\begin{abstract}
Unschooling caracteriza uma forma de educar dentro ou fora de casa (em relação com diversos espaços, atividades, instrutores, etc.) rompendo com os modos de fazer presentes no sistema regular de ensino (priorizando que a criança escolha o que, como, e quando quer aprender e criando maneiras outras de se relacionar com o conhecimento). (GONÇALVES, 2016, p. 86).
\end{abstract}

Ainda segundo Gonçalves (2016, p. 85): "John Holt foi o responsável pela atribuição do termo unschooling ao campo de práticas educacionais formais fora da escola". Conforme apregoa Farenga (2013b), Holt possivelmente queria aproximar a palavra à dimensão natural do aprendizado. O termo "dimensão natural do aprendizado" (GONÇALVES, 2016, p. 85) envolve aspectos associados a um processo de educação fora dos padrões curriculares formais estabelecidos pela Legislação, levando em consideração o desenvolvimento natural do indivíduo e seus interesses.

No Brasil, alguns autores, como Salgado (2018), apresentam os termos desescolarização e unschooling como sinônimos, levando em conta a variação linguística na tradução, "[...] referência do que tem sido denominado no Brasil como desescolarização e, nos países de língua inglesa, como 
unschooling” (SALGADO, 2018, p. 71). As nomenclaturas, muitas vezes, são erroneamente interpretadas e traduzidas, como no caso dos termos desescolarização e unschooling, que correspondem a práticas distintas (MONRAT, 2018).

No entanto, o unschooling perpassa pelo caminho da desescolarização, pois, segundo Monrat (2019), a desescolarização é o período de transição entre escolarização e unschooling, ou até mesmo uma opção para outros tipos de "dependência" (homeschooling). Nesse sentido, o processo de desescolarização é parcialmente livre da ideia escolar no que diz respeito à ação, mas nem sempre no que tange ao pensamento e ao sentimento, porque ainda há vínculo com paradigmas limitantes que não confiam totalmente na individualidade (MONRAT 2019).

Prosseguindo a discussão sobre os conceitos e os significados da prática em tela, alguns autores, a exemplo de Pessoa (2019, p. 63), apresentam o unschooling como um "método pedagógico" praticado por famílias homeschoolers, “[...] que não se apropria dos aparatos da escola [...]" e "[...] propõe uma abordagem livre e ampla da aprendizagem". Dentre os métodos praticados pelas famílias homeschoolers, o autor cita "Unschooling, Charlotte Mason, Educação clássica e Escola em casa" (PESSOA, 2019, p. 55). Pessoa (2019) organiza e compara as características desses "métodos pedagógicos" homeschoolers em um quadro (Figura 1), no qual é possível ver a prática unschooling classificada como tal:

Figura 1 - Síntese dos métodos pedagógicos homeschoolers apresentado por Pessoa (2019)

\begin{tabular}{|c|c|c|c|c|}
\hline Método & Currículo & $\begin{array}{l}\text { Relação de } \\
\text { ensino }\end{array}$ & Avaliação & Ênfase \\
\hline Escola em Casa & $\begin{array}{l}\text { Base Nacional } \\
\text { Comum } \\
\text { Curricular } \\
\text { (BNCC) }\end{array}$ & $\begin{array}{l}\text { Pais como } \\
\text { professores }\end{array}$ & $\begin{array}{l}\text { Continua e } \\
\text { Provas }\end{array}$ & $\begin{array}{c}\text { Transferência da } \\
\text { estrutura escolar } \\
\text { para casa }\end{array}$ \\
\hline $\begin{array}{c}\text { Educação } \\
\text { desescolarizada } \\
\text { (Unschooling) }\end{array}$ & Sem currículo & $\begin{array}{c}\text { Não há } \\
\text { professor, os pais } \\
\text { ensinam } \\
\text { acompanhando } \\
\text { os interesses das } \\
\text { crianças }\end{array}$ & Sem avaliação & $\begin{array}{c}\text { Liberdade e } \\
\text { autodescoberta }\end{array}$ \\
\hline $\begin{array}{c}\text { Método Clássico } \\
\text { Medieval }\end{array}$ & $\begin{array}{l}\text { Trivium e } \\
\text { Quadrivium }\end{array}$ & $\begin{array}{l}\text { Mestre e } \\
\text { discípulo }\end{array}$ & Oral e escrita & $\begin{array}{l}\text { Adquirir a } \\
\text { verdade }\end{array}$ \\
\hline $\begin{array}{l}\text { Método Clássico } \\
\text { Contemporâneo }\end{array}$ & $\begin{array}{l}\text { Trivium aplicado } \\
\text { às matérias e às } \\
\text { fases de } \\
\text { desenvolvimento } \\
\text { da criança e } \\
\text { podem ou não se } \\
\text { referenciar pela } \\
\text { BNCC }\end{array}$ & $\begin{array}{l}\text { Educador e } \\
\text { Educando }\end{array}$ & $\begin{array}{l}\text { Contínua, } \\
\text { podendo ou não } \\
\text { fazer uso de } \\
\text { provas }\end{array}$ & $\begin{array}{l}\text { Aprender a } \\
\text { aprender }\end{array}$ \\
\hline
\end{tabular}

Fonte: Pessoa (2019, p. 75).

Os dados apresentados por Pessoa (2019, p. 75), que trata a prática do "[...] unschooling como um método pedagógico dentro do homeschooling”, são no mínimo controversos, tendo em vista os conceitos associados ao próprio unschooling, cuja base se caracteriza pela estranheza ao formato escolarizado e pela ausência de formas pré-definidas ou currículo delimitado. Em sua pesquisa, o próprio Pessoa (2019) descreve o unschooling como uma desescolarização da estrutura escolar. Nesse sentido, Monrat (2018) parece associar o unschooling a questões relacionadas a uma jornada profunda de autoconhecimento, e não ligadas a um sistema. 
Se o unschooling, como prática de estudo, está ligado a uma jornada diária e intensa de autoconhecimento, a mediação cultural pode ser compreendida como "[...] um importante instrumento para a formação artística, estética e, também, política das pessoas que frequentam os espaços educativos, sejam eles os espaços formais ou não formais de ensino, e [...] ela pode promover a autonomia do sujeito" (KUPIEC; NEITZEL; CARVALHO 2016, p. 28-29, grifo nosso).

Para entender melhor a relação entre unschooling e mediação cultural, é preciso ter ciência de que, "[...] tanto na escola como em qualquer outro espaço educativo, o processo de mediação cultural deve ser o entrecruzamento de conhecimentos artísticos, estéticos e políticos" (KUPIEC; NEITZEL; CARVALHO, 2016, p. 29), possibilitando, por meio da arte, a emancipação e a formação geral do ser humano (KUPIEC; NEITZEL; CARVALHO, 2016).

Portanto, olhamos para o percurso da adolescente em seu cotidiano em busca de compreender os caminhos da mediação cultural nesse processo de unschooling, a fim de refletir, neste artigo, acerca de conceitos e de lugares que se atravessam e se entrelaçam, como a mediação cultural e a prática do unschooling.

Não partilhamos da opinião de que a arte se aprende somente na escola, pelo contrário, mas compreendemos que parte do conhecimento sistematizado sobre tal é vivido no contexto escolar, sendo importante pensar o processo de mediação cultural neste e nos outros espaços como contribuinte para o fortalecimento da produção, da dinamização, da interação e da diversidade metodológica, que impulsionam a formação estética e artística dos sujeitos envolvidos (KUPIEC; NEITZEL; CARVALHO, 2016).

Nesse processo de unschooling, a família mencionou as aproximações da adolescente com a Arte, talvez muito mais frequentes e intensas do que aquelas que a escola lhe possibilitava. Nesse sentido, percebemos um ponto curioso a ser investigado, que nos toca e nos provoca: Até que ponto ou em que momentos a jovem está ou não tendo acesso à arte? Por quais percursos? De que maneira?

Acreditamos na importância da Arte e em seu poder de "[...] levar o ser a perceber que é transformador, que possui um imenso potencial criativo e artístico" (OLIVEIRA, 2014, p. 106, grifo nosso), transformação para a qual a mediação cultural pode ser a chave, permitindo encontros sensíveis e possibilitando outros pontos de vista e significações (URIARTE et al., 2016). A mediação cultural, nesse viés, é " [...] um convite para vermos vendo, sentirmos sentindo, percebermos pensando" (MARTINS, 2014, p. 260).

Kupiec, Neitzel e Carvalho (2016) acenam uma rede de mediação cultural no qual há relação entre espaços educativos não formais e formais, como escolas e universidades em processos que promovem conhecimentos artísticos, estéticos e políticos. As autoras destacam o papel do professor como mediador nos espaços de mediação cultural. Assim como outros sujeitos, o professor possui um valor simbólico no jogo cultural em que estamos inseridos (KUPIEC; NEITZEL; CARVALHO, 2016). Nesse sentido, olhar para um processo de unschooling provocanos a olhar um processo em que o professor ou a escola saem de cena e outros atores entram para atuar.

Como as autoras, continuamos a nos questionar sobre esses percursos, como eles são percorridos e elaborados. Desejamos compreender como essa jovem se relaciona com a arte em seu entorno. 


\section{Aspectos da prática do unschooling no cotidiano da família investigada}

Para viver este processo em que a adolescente se inseriu, e aqui nos referimos à prática do unschooling, é necessário "[...] desestruturar, para somente depois entender por onde se quer caminhar" (MONRAT, 2018, p. 119, grifo da autora). É o que procuramos neste estudo, sem intenção de fazer julgamentos, classificações ou comparações entre práticas e/ou crianças e adolescentes dentro ou fora da escola. Segundo Monrat (2018, p. 113), “[...] estamos falando de dinâmicas diferentes e que se forem avaliadas com respeito e competência, facilmente se perceberá que elas estão pautadas em critérios distintos, portanto incomparáveis". Desse modo, não há possibilidades de comparação entre as crianças que vivem na escola e as que vivem o unschooling.

Para compreender a prática do unschooling no cotidiano de seus adeptos, é preciso, antes de tudo, entender que ele não é escola, portanto não se trata de um modelo escolarizado fora do espaço físico escolar. Cumpre olhá-lo com outros olhos, "sair da caixa" (MONRAT, 2018), sem buscar comparações. Voltamos novamente ao conselho de Monrat (2018, p. 131) em relação às práticas: "[...] se for criada uma nova caixa, fazer comparações entre crianças de diferentes caixas, sendo uma escolarizada e outra de livre aprendizagem, é um tiro no pé”.

Por tratar-se do estudo de um caso específico, não há a intenção, a partir dos dados gerados, de universalizar ações ou percursos do cotidiano das famílias unschooler. Entendemos também, conforme menciona Loreti (2019, p. 18), a partir do desabafo de uma mãe, que não se trata de um "[...] método de ensino, mas sim de uma mudança que diz respeito a todos os aspectos da vida". Assim sendo, cada família organizará, em seu dia a dia, o trajeto que melhor atenda às demandas dos sujeitos envolvidos na prática. O fato de não existir uniformidade no trajeto cotidiano escolhido pelas famílias unschooler foi justificado pelo pai da adolescente por ocasião da entrevista, ao se referir à inexistência de um modelo único, padrão, que sirva de maneira igual a todos os seres humanos, tanto no unschooling como na escola:

[...] nada do mundo existe e vai servir perfeitamente pra todo mundo, porque nós somos seres humanos totalmente diferentes uns dos outros, constituições biológicas e uma série de outras coisas que nos fazem totalmente diferentes e, por isso, não vai existir nenhum modelo que vá servir pra todo mundo. (P, 2019, informação oral). ${ }^{3}$

Para Monrat (2018, p. 48) e para a família, o cotidiano do unschooling é uma espécie de desintoxicação, "[...] é ir além das questões sobre a educação dos filhos, é mudar o modo de vida, é criar opções completamente diferentes, é tentar meios e situações nunca antes pensados. É começar novas jornadas dentro de outras perspectivas". Transformar o modo de vida, pensar novas situações e jornadas não diz respeito somente às crianças e/ou aos adolescentes inseridos na prática, pois também inclui um projeto familiar. Embora a criança e/ou adolescente seja o centro do ensino, toda a estrutura familiar se organiza e se transforma para essa prática. Em função disso, tudo muda, segundo revelou a mãe da adolescente durante a entrevista:

[...] a própria profissão foi mudando, as nossas [pausa], o jeito como a gente enxergava as coisas, não faz sentido a gente fazer isso com ela [a filha], né? A gente acreditar tanto nisso e a gente fazer para as pessoas tal e tal coisa, assim, no trabalho, então foi uma mudança que foi acontecendo [...]. (M, 2019, informação oral). ${ }^{4}$

Para os pais, é um projeto em que eles acreditam; logo, para ser posto em prática, a família toda precisa mudar o olhar, porque "[...] tu tá em contato 24 horas com teu filho, né? Então não tem esse

\footnotetext{
${ }^{3}$ P. Entrevista I. [2019]. Entrevistadora: Helen R. L. R de Souza. Blumenau, 2019. 1 arquivo .mp3 (9:36 min) em posse da autora. Todas as menções ao "P" feitas neste artigo dizem respeito à entrevista em questão.

${ }^{4}$ M. Entrevista II. [2019]. Entrevistadora: Helen R. L. R. de Souza. Blumenau, 2019. 1 arquivo .mp3 (7:50 min) em posse da autora. Todas as menções à "M" feitas neste artigo dizem respeito à entrevista em questão.
} 
distanciamento. [...] eles estão em contato com nossos problemas, eles vivenciam a nossa vida o tempo todo. O que tá acontecendo e tal' (M, 2019, informação oral).

Por essa proximidade, os pais dizem que passaram a "[...] conhecer melhor os filhos, nos gostos, habilidades, personalidades... mais intimamente" (Diário de Campo, 2019). Loreti (2019) afirma que, no cotidiano do unschooling, a vida diária funde-se à vida voltada ao alcance de determinados conhecimentos e habilidades necessários para estar no mundo.

Durante a entrevista, foi perguntado aos pais: "Como é organizado o dia a dia da família?". Eis a resposta:

\begin{abstract}
Primeiro, não existe uma organização de aprendizagem, isso não existe. É no ritmo dela [adolescente]. Exceto as aulas, né, que ela faz, particulares, aulas de música, aula de inglês e outras que ela já fež, on que agora ela quer fazer. Existe um [pausa], eu acredito, né, estando com eles o tempo todo em casa, que um ritmo é importante. Então existe um ritmo que acontece para que as coisas funcionem. É. Cada um tem as suas atividades em casa, assim, da rotina da casa mesmo, domésticas, que eu acredito que são muito importantes para eles enquanto seres humanos, e ai eles fazem isso. Essa rotina, ela também não é uma rotina "estanque". Assim, ela vai mudando, conforme o ritmo da família, conforme o meu ritmo e do pai. (M, 2019, informação oral).
\end{abstract}

Essa "não organização" da aprendizagem, ressalvada a existência de um "ritmo familiar", é porque esse processo se faz "[...] construindo juntos, conforme forem aparecendo os desejos e as curiosidades, e não delegando ou oferecendo situações 'do nada" (MONRAT, 2018, p. 59- 60). Assim, para o unschooling, esse ritmo familiar é um meio de viver as experiências almejadas "[...] é uma maneira de você estimular e extrair do seu filho profundamente suas capacidades, de acordo com o que ele te mostra” (Diário de Campo, 2019), ser perceptível às necessidades e aos interesses dos filhos e, a partir disso, o ensino é construído.

A família menciona outro fator importante para esse "ritmo familiar", que está associado ao "tempo de qualidade" para as trocas de experiências: "ter esse tempo, né, pra observar eles, pra entender o que tá acontecendo" (M, 2019, informação oral).

Quando a mãe mencionou a troca de experiência em uma simples caminhada ao mercado próximo de sua casa, ela contou

[...] que o filho mais novo observava as plantinhas e fazia as comparações enquanto que com a filha, hoje adolescente, não teve isto... do conhecimento e aprendizado nestas experiências, pois estava sempre correndo de casa para a escolinha e depois trabalho, entrava e saía do carro sem perceber o que poderia ser descoberto. (Diário de Campo, 2019).

De acordo com os pais, a prática é muito mais trabalhosa do que deixar os filhos na escola, pois você se predispõe a participar ativamente do processo de ensino. Então, segundo eles, “[...] o argumento de que o homeschooling ou unschooling é uma opção de pais preguiçosos não se encaixa nessas demandas" (Diário de Campo, 2019). Nesse sentido, o termo "presença" é citado pelos pais como a característica principal do ensino no unschooling. Em sua pesquisa, Loreti (2019) menciona que o termo "presença" é recorrente na fala dos adultos de uma família unschooler, entendido então como uma demanda das crianças por atenção às suas falas e às suas necessidades. O adulto precisa ter "presença" que garanta às crianças um ambiente estimulante para o desenvolvimento da sua vontade de aprender. Nesses termos, os adultos não lhes dizem o que aprender, mas estão atentos, em razão da "presença", às suas necessidades, às suas demandas e às suas curiosidades. E só então, segundo Monrat (2018),

[...] quando as infindáveis perguntas se revelarem, é que você [adulto] deve aparecer, estar presente e à disposição. Esse é o momento real da sua participação na aquisição de

Práxis Educativa, Ponta Grossa, v. 15, e2014790, p. 1-19, 2020 Disponível em: < https://www.revistas2.uepg.br/index.php/praxiseducativa> 
conhecimentos da criança. É quando a criança pergunta algo que faz sentido para ela saber naquele momento, na entrega prazerosa da experiência individual. (MONRAT, 2018, p. 72).

A fim de compreender ainda melhor o dia a dia da família, perguntamos aos pais durante a entrevista: "Quais as facilidades e as dificuldades encontradas na organização desse cotidiano? ". Ambos afirmaram encontrar potencialidades e se deparar com dificuldades como em qualquer outra prática, conforme relatado pelo pai da adolescente: “[...] obviamente, todos os modelos vão ter prós e contras, né?" (P, 2019, informação oral). Quanto aos potenciais da prática, tanto a adolescente quanto os pais citaram a flexibilidade de horários.

A maleabilidade em relação aos horários mencionada pela família possibilita desfazer a lógica da sociedade pós-industrial, que Touraine (1994) chama de "Sociedade Programada". Nessa sociedade, a vida está envolta em uma logicidade ditada pela produção e pela difusão em massa das representações, das informações e das linguagens, que nos dizem o que consumir, como nos vestir, em que acreditar, como nos comportar em determinados ambientes, inclusive o horário para determinadas atividades. Portanto, para viver o cotidiano do unschooling, "[...] o sujeito se coloca por oposição à lógica do sistema" (TOURAINE, 1994, p. 377). Não que sujeito e sistema estejam separados, mas, sim, em movimentos sociais opostos.

Em contrapartida, essa facilidade em relação aos horários pressupõe uma "[...] disponibilidade maior para eles [filhos]" (P, 2019, informação oral), inclusive emocional, pois "[...] criança esgota, né, emocionalmente esgota, porque tu tens que estar ali disponivel o tempo todo" (M, 2019, informação oral). Nessa perspectiva, a mãe da adolescente menciona que, muito embora o ritmo da família estruture a prática, ela vê esse fato como dificuldade, pois, quando uma coisa muda, tudo muda.

Ligada ao fator dinâmico do ritmo familiar e cotidiano, a adolescente citou durante a entrevista uma de suas dificuldades:

[...] as minhas dificuldades são - porque, como eu não tenho, assim, um lugar fixo para ir, algo que eu, eu meio que seja obrigada a fazer todos os dias -, muitas vezes, eu acabo me perdendo no meio do caminho, assim. E aí, quando eu faço planos, por exemplo: - "ab!, eu quero acordar nesse horário e eu quero estudar isso, sobre isso, de tarde", sempre acaba acontecendo alguma coisa que eu não consigo, sabe? [...] (A, 2019, informação oral). ${ }^{5}$

Monrat (2018, p. 68, grifo da autora) menciona que, “[...] para as crianças, a imersão na vida unschooling é intensa, e o ritmo e a qualidade da relação conta muito, criando marcas para o resto na vida". Esse ritmo e essa qualidade na relação pressupõem também um ambiente favorável e estimulante, que contribua para essa imersão na prática. Buscamos então compreender aspectos desse ambiente na residência da adolescente, sob a óptica de que o unschooling não é a "casa como escola" (LORETI, 2019, p. 117) ou "trazer a escola para dentro de casa" (SALGADO, 2018, p. 135).

Em razão desse fator, a mãe da adolescente enfatizou, durante a entrevista, que não pretende ser professora dos filhos:

De qualquer maneira, eu não me vejo também educando meus filhos em casa como uma professora, não é isso que eu quero, eu não vou praticar homeschooling com eles, porque eu não tenho vontade e não tenho também essa habilidade, né, para faz̧er isso. (M, 2019, informação oral).

Entretanto, alguns registros fotográficos da casa indicam que, mesmo a mãe não desejando ser a professora dos filhos, aspectos da escola estão presentes na casa da família, como: quadro

\footnotetext{
${ }^{5}$ A. Entrevista III. [2019]. Entrevistadora: Helen R. L. R. de Souza. Blumenau, 2019. 1 arquivo .mp3 (1:40 min) em posse da autora. Todas as menções à "A" feitas neste artigo dizem respeito à entrevista em questão.
} 
negro, amarelinhas e caixas de areia. Durante a entrevista, a mãe da adolescente assim se pronunciou sobre esse particular "Tu tiras da escola, mas a escola não sai de dentro de ti, porque nós todos somos escolarizados” (M, 2019, informação oral).

Diante desses dados, relacionando-os com a fala da mãe, podemos perceber alguns conflitos presentes nesse processo, no qual desejo e realidade se fundem. Segundo Monrat (2018, p. 69), "[...] é difícil, extremamente difícil, desconstruir a estrutura pedagógica de dentro de um adulto. Ela está tão misturada como nosso sangue, que não sabemos mais o que é nosso e o que é da toxina". Sob outra perspectiva, seria um habitus (BOURDIEU, 2004), origem de um conhecimento sem consciência, de uma intencionalidade sem intenção; desse modo, um gerador de práticas daquilo que ele carrega consigo imediatamente ajustado ao presente.

\section{Teia de relações: unschooling e os percursos de mediação cultural e sua aproximação com a arte}

Apresentamos questões relacionadas ao conceito de unschooling e suas nomenclaturas díspares, incluindo desescolarização. O termo "desescolarização", que, no Brasil, por vezes, é associado ao unschooling, está relacionado aos ideais de Illich (1985) mencionados em Sociedade sem escolas. Partindo desse lugar, entremeado ao unschooling, mas distinto do unschooling, é possível entender as críticas de Illich (1985) contra o processo de escolarização e sua proposta de ruptura com o sistema escolar por meio da desescolarização, bem como os motivos pelos quais a escola deveria ser desinstalada de seu modelo tradicional:

\footnotetext{
1. Porque devemos desinstalar a escola

[...] ela os escolariza para confundir processo com substância. Alcançado isto, uma nova lógica entra em jogo: quanto mais longa a escolaridade, melhores os resultados; ou então, a graduação leva ao sucesso. O aluno é, desse modo, <escolarizado $>$ a confundir ensino com aprendizagem, obtenção de graus com educação, diploma com competência, fluência no falar com capacidade de dizer algo novo. (ILLICH, 1985, p. 21).
}

Segundo Illich (1985, p. 23), “[...] não apenas a educação, mas também a própria realidade social se tornou escolarizada". O termo "escolarizado", na acepção que Illich (1985) lhe confere, refere-se a um sistema de educação modelo que se tornou massificado, que serve a um produtopadrão como resultado. Diante disso, o autor propõe " [...] uma revolução educacional [...]: nova orientação das pesquisas e nova compreensão do estilo educacional de uma contracultura emergente" (ILLICH, 1985, p. 120). Diante da proposta de contracultura e revolução educacional, Illich (1985, p. 47) sugere um novo sistema de aprendizagem, que seria "[...] uma rede ou um sistema de serviços que desse a cada homem a mesma oportunidade de partilhar seus interesses com outros motivados pelos mesmos interesses".

Illich (1985), p. 48) sugere, portanto, “[...] congregar pessoas de acordo com seus interesses sobre determinado assunto [...]". O que acontece no unschooling, segundo Loreti (2019), pois a organização em série e idades se desfaz e produz outras relações aquém daquelas estruturadas por uma pedagogia tradicional, fundamentada no desenvolvimento físico-cognitivo. Em suas próprias palavras, Illich (1985, p. 120) propõe como "[...] alternativa sintática uma rede ou teia educacional que permite a reunião autônoma de recursos sob o controle pessoal de cada aprendiz".

6. Teias de aprendizagem

[...] de que podemos depender de aprendizagem automotivada em vez de contratar professores para subornar ou compelir o estudante a encontrar tempo e vontade para aprender; de que podemos fornecer ao aprendiz novas relações com o mundo, em vez de continuar canalizando todos os programas educacionais através do professor. (ILLICH ,1985, p. 123-124).

Práxis Educativa, Ponta Grossa, v. 15, e2014790, p. 1-19, 2020 Disponível em: < https://www.revistas2.uepg.br/index.php/praxiseducativa> 
Coincidentemente, sobre a mesma figura/símbolo da "teia" ou "rede", Kupiec, Neitzel e Carvalho (2016, p. 28), que tratam dos conceitos de mediação cultural, tecem um esquema denominado "rede de espaços educativos" (Figura 2). No esquema, as autoras mencionam possíveis locais de educação e mediação cultural, por exemplo, praças, teatros, escolas, universidades, galerias, cinemas, museus e bibliotecas.

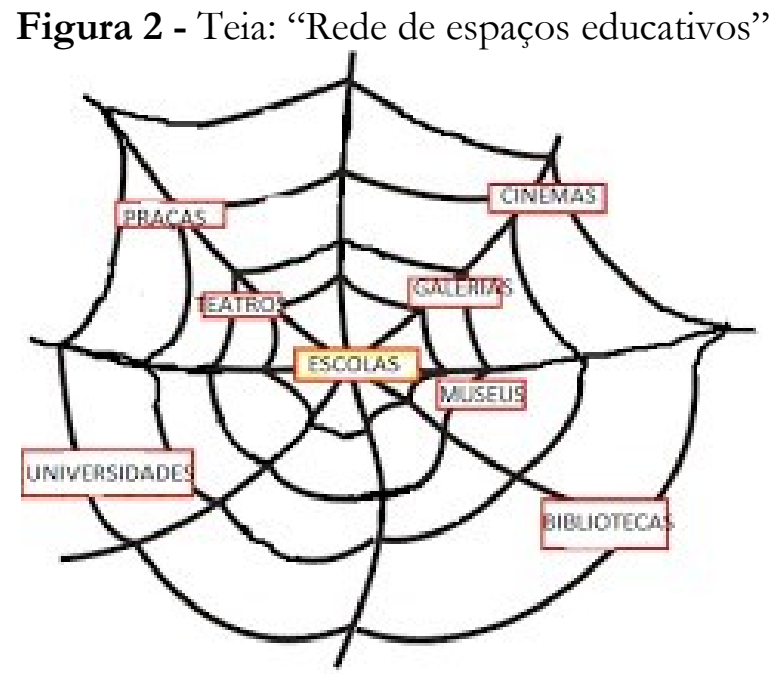

Fonte: Kupiec, Neitzel e Carvalho (2016, p. 28).

Tendo em vista essa figura da "teia de aprendizagem", proposta tanto por Illich (1985) quanto pela "teia/rede de espaços educativos" das autoras citadas, propomo-nos a pensar o lugar (ou os lugares) de relação com o unschooling. Poderia o unschooling formar uma nova "teia" para as relações de aprendizado? Quais seria(m) o(s) percurso(s), nessa teia, para a mediação cultural na relação com a arte dentro da prática do unschooling?

Para Kupiec, Neitzel e Carvalho (2016), a mediação cultural é pensada como fonte de liberdade e de autonomia exercida no encontro, no diálogo entre a arte e o público. Nesse sentido, alguns fios começam a surgir no percurso, como indicadores de uma teia da mediação cultural no unschooling. Palavras e expressões como "seus interesses e liberdade", "autonomia", "rede de pessoas e mediadores", "locais de exposição tais como museus e teatros", "internet como mediadora" e "aulas em espaços não formais" aparecem associadas nesse trajeto e serão apresentadas na sequência, visando a uma reflexão acerca desses conceitos e lugares que, nesta pesquisa, atravessam-se e entrelaçam-se com a prática do unschooling. A seguir, descrevemos como esses indicadores emergem dos dados e, com isso, como a teia começa a ser tecida.

\section{$\checkmark$ Seus interesses e liberdade}

A adolescente mencionou durante a entrevista que seus interesses divergem daqueles que cultivava quando ainda estava na escola justamente pela liberdade de escolha, "[...] porque na escola estão sempre te mandando fazer alguma coisa, tu não usas tua criatividade pra pensar: - 'Olha eu tenho interesse nisso, eu vou estudar isso"' (A, 2019, informação oral). Ao passo que a estrutura da casa, segundo a adolescente, é um gatilho para o interesse: "[...] acordar todo dia e pensar: - 'Meu, preciso estudar alguma coisa, né, porque eu tô em casa, eu quero estudar, en sinto vontade. E agora, o que que eu vou estudar?' Então vou lá, pesquiso sobre as coisas que eu tenho interesse" (A, 2019, informação oral). A adolescente também se posicionou em relação ao seu comportamento, que seria mais livre no unschooling: "[...] en acho que en mudei muito da escola e, agora, assim, en me sinto bem mais livre do que [pausa] na escola en me sentia presa, 
sabe? E agora en me sinto livre para fazer as coisas que en quero. Eu acho que en mudei bastante" (A, 2019, informação oral).

Observamos que os conceitos de liberdade de escolha e tempo livre são muito presentes nas falas da adolescente. Touraine (1994) apregoa que devemos compreender uma sociedade a partir de como os sujeitos produzem a sua história e, nesse sentido, pensar e investigar a sociedade de acordo com sua dinâmica interna. Para o autor, o que está em foco é pensar a ação, e não a situação (TOURAINE, 1994). Nesse sentido, há na família uma escolha, uma ação que coloca a adolescente na condição de poder escolher e decidir o que faz do seu tempo.

Em seu diário pessoal, compartilhado digitalmente, a adolescente descreve algumas atividades pelas quais demonstra interesse, como canto, música, pintura, desenhos e atividades de física e astronomia:

Compus uma música, e vou pegar um teclado pra terminar ela, quando eu terminar te mando o vídeo [...]. Continuo compondo músicas e já decidi com quem vou fazer aula de canto com a professora na escola $\mathrm{ABC}$, ela é amiga da mãe do meu amigo [com] que $[\mathrm{m}]$ costumo falar por aqui. [...]. Continuo sempre, pintando e desenhando é um momento onde me sinto calma e gosto de expressar o que sinto no papel [...]. Tenho cantado muito, feito muito karaokê, porque eu amo e quase todo dia eu tiro um tempinho pra cantar. Desenho bastante também, ultimamente desenhos de montanhas de gelo kkkk [...] coisas relacionadas à arte eu gosto muito, e... eu acho que coisas relacionadas à arte, eu acho muito legal. (Diário de A, 2019).

Segundo a adolescente, seu interesse por física liga-se ao estudo da astronomia, conforme mencionou na entrevista, "[...] en quero começar a fazer física, eu até comentei lá no diário, né [...] Então eu vou procurar um professor de física [...] porque en adoro astronomia, e é difícil assim, estudar sobre astronomia sožinha" (A, 2019, informação oral). A adolescente também mencionou que as atividades que a atraem são frutos de seus próprios interesses, sem intervenção dos adultos.

\section{$\checkmark$ Autonomia}

Percebemos, a partir dos dados, que a escolha e o percurso exigem autonomia, porque envolvem não só a arte e a mediação cultural, mas todos os conhecimentos. Na entrevista, a adolescente mencionou aspectos da autonomia que desenvolveu com a prática do unschooling:

[...] é que eu aprendi a falar não, assim. Porque, na escola, eu acabava sofrendo muito, porque eu sempre tava aceitando as coisas, sabe? E eu nunca falava nada que eu não gostava, sempre ficava mais quieta. Eu hoje, saindo assim, eu acho que eu [pausa], eu aprendi a me comunicar melhor assim, e se eu sei quando dizer as coisas que eu não quero, sabe, eu sei me posicionar melhor, eu acho. (A, 2019, informação oral).

Outro fator mencionado em relação à autonomia foi o momento para estudar e conhecer a si, como destacado na entrevista:

[...] então, eu mesma entendo: - "Poxa eu tô precisando estudar, tô precisando ler mais". Às vezes, eu paro de ler, eu tô pensando em fazer isso, aquilo, mais atividade. Então eu vou propondo, sabe? Eu acho legal isso, [por]que en vou aprendendo a lidar com meus sentimentos também, sabe? (A, 2019, informação oral).

Segundo a adolescente, foi a partir dessa autorreflexão que passou a compreender suas necessidades, propondo-se, de maneira autônoma, a supri-las. Percebemos que a adolescente faz suas escolhas, define seus professores em espaços outros que não sua casa e participa de outros grupos, por exemplo. 


\title{
$\checkmark$ Rede de pessoas, mediadores
}

Percebemos, na pesquisa, que o unschooling não se faz sozinho, fato que nos remeteu aos discursos sobre socialização que afetam a educação fora da escola. Notamos que a família investigada forma uma rede de apoio composta por pessoas que se relacionam em prol da educação de uma criança ou de um adolescente.

Durante os percursos de observação, entrevistas e análises do Diário da Adolescente, foi possível perceber que, nessa família, há uma rede de pessoas que se envolvem com a educação das crianças. Além da adolescente, há ainda outras duas crianças na família. Uma das quais pequena, de cinco anos; e outra, um bebê. Percebemos que, por vezes, essas pessoas se relacionam não somente com a adolescente que optou pelo unschooling, mas também com as outras crianças da família. Há uma relação, um processo de mediação que se espalha no contexto. A família da adolescente participa de uma rede de apoio e se encontra com outras famílias que escolheram o mesmo tipo de educação para seus filhos. De alguma forma, constatamos que, nesse contexto, há processos, escolhas e trocas que possibilitam reflexões sobre o que fazer com os filhos em casa.

Essa rede de pessoas forma o que chamamos de "rede educacional", que colabora para a aprendizagem a partir dos interesses do sujeito. Alguns são citados, nesta pesquisa, como "amigos de estudo ou tutores" ou "grupo". No Diário, a adolescente faz referência a uma "amiga de estudo": "Beka, que é nossa, digamos, 'tutora', que aqui chamamos 'amiga de estudo', chegou para ficar com meu irmão, porque hoje foi o dia dele” (Diário da A, 2019). Na entrevista, a adolescente deu mais detalhes sobre as ações que desenvolve com a colaboração da "amiga de estudo":

[...] eu pensava no que eu queria estudar, e a gente - mesmo que ela não soubesse sobre aquele assunto, ela sentava comigo - e a gente pesquisava juntas, sabe, sobre aquilo e aprendia juntas. E ela aprendia coisa que ela não sabia também. Então, é claro, ela também vinha com ideias, e a gente faz̧ia, era bem legal. (A, 2019, informação oral).

Outras pessoas colaboram com a rede educacional, ou o "grupo", 6 como mencionado pela adolescente na entrevista:

\begin{abstract}
Ah! Aquele grupo, ele era muito legal. Assim, nós tínhamos crianças, eram [interrompe] que praticavam homeschooling, que praticavam o unschooling, e todo mundo se juntava - acho que era toda sexta-feira) - para brincar, assim, sabe? A gente criava coisas e se juntava também no final daquela brincadeira, para pensar, e cada um escrevia no caderno alguma coisa que queria fažr. [...] Então todo mundo ia juntando as ideias ali, e toda semana a gente ia pensando: - "Tá, agora, qual [atividade] a gente faz essa semana?". Mas [eram] as crianças que organizavam assim. - "Então, vamos fazer essa semana esse, depois a gente faz o da Camila". E ai a gente [pausa], toda a sexta, ia fazendo alguma coisa diferente: às vezes se juntava pra brincar, às vežes ia a um museus, on ia a alguma dessas ideias que que eles falaram e [pausa] era muito legal assim. (A, 2019, informação oral).
\end{abstract}

De acordo com a adolescente, o "grupo" possibilita um encontro entre as pessoas, que, de maneira autônoma, decidem suas atividades, tornando-se um propulsor da aprendizagem. Em sua pesquisa, Loreti (2019) menciona diversos grupos tidos como grupos de apoio às famílias que optaram pela educação fora da escola.

\footnotetext{
${ }^{6}$ Trata-se de um coletivo de famílias adeptas do ensino fora da escola e simpatizantes das suas práticas, que se encontra para discutir diversos assuntos referentes à educação fora da escola. Os encontros não têm data fixa e acontecem de acordo com as demandas das famílias.
}

Práxis Educativa, Ponta Grossa, v. 15, e2014790, p. 1-19, 2020 Disponível em: < https://www.revistas2.uepg.br/index.php/praxiseducativa> 


\section{$\checkmark$ Locais de exposição tais como museus e teatros}

Alguns trajetos de visitação são citados pela adolescente em seu Diário: “[...] quando chegamos lá, decidimos ir ao Mausoléu Doutor Blumenau [...]. Depois do Mausoléu, fomos à feirinha da servidão [...] e fomos à Festa da Primavera. Foi lá no Ipevi [Instituto de Permacultura do Vale de Itajai]" (Diário da A, 2019)

Outros locais, sugeridos e decididos em comum acordo com o grupo, foram mencionados pela adolescente na entrevista:

[...] a gente costumava ir mais aos museus, muito por causa do grupo, porque todas nós, crianças, a gente se juntava e pensava no que a gente tinha interesse em fazer. Então, a gente ia ver os museus, e os museus [em] que eu tinha interesse, que eu ia só com a minha familia, eram museus que nós todos, assim [pausa], porque aqui em casa todo mundo vai compartilhando, assim, sabe? (A, 2019, informação oral).

$\mathrm{Na}$ entrevista, a adolescente destacou os passeios realizados, por exemplo, na feirinha da servidão: "[...] esses nossos passeios, ir lá na feirinha, é uma delícia, assim, sabe? Tem muita arte, é muito legal. Todo mundo tem assim [fica pensativa] um clima muito gostoso, sabe, lá na feirinha. Na feirinha, a gente costuma ir bastante, porque é muito legal lâ" (A, 2019, informação oral). De igual modo, a adolescente também falou sobre os passeios que pretende fazer: "Mas a gente está inclusive pensando em ir lá no museu da água. Faz um tempo que a gente não conseguiu ir. Porque eu acho muito interessante, sabe? Eu quero entender como tudo isso funciona" (A, 2019, informação oral).

\section{$\checkmark$ Internet como mediadora}

No percurso de estudos da adolescente, a internet, incluindo os aplicativos para celulares e os canais do YouTube, aparece como mediadora desse processo. Em seu Diário, a adolescente menciona seus interesses e as diversas vezes que, partindo deles, recorreu às ferramentas da internet como mediadora para seu processo de estudo. Como seus principais interesses variam entre música, astronomia e história, a adolescente utiliza a internet como instrumento para avançar em seu aprendizado nessas áreas. Por exemplo, quando menciona:

[...] eu pesquisei sobre o Canadá, comecei um projeto de estudar todos os países, estou começando pela América do Sul, Norte e Central.

[...] bom, essas são algumas das coisas que eu estou estudando e tentando achar no céu, estou usando um aplicativo muito legal, o Cartes de Ciel, que me diz todas as constelações que estão em cima de mim, as estrelas, em que direção estão os planetas e muito mais, é super legal.

Hoje estudei física, vejo um canal chamado Manual do Mundo, é bem legal, eles fazem vários experimentos e depois explicam como acontece[...]. (Diário da A, 2019).

Os aplicativos e os canais de acesso na internet utilizados pela adolescente também servem como forma de estudo e aperfeiçoamento do idioma inglês:

Queria também compartilhar com você alguns aplicativos que tenho no meu celular, que uso bastante, um deles é o Breaking News, um aplicativo onde consigo ver tudo que está acontecendo no Canadá, notícias, alertas, tempo, jornal, etc. Também uso bastante o aplicativo da Nasa, onde vejo todas as descobertas deles, o aplicativo Solar System, que me diz onde os planetas, estrelas, galáxias, constelações estão bem em cima de mim, outro chamado Corpo Humano, onde tem o sistema digestivo e sistema circulatório, e ele mostra tudo em 3D e explica. Ele é em inglês, então além de aprender sobre o corpo humano, eu fico treinando o meu inglês. E, por último, um jogo chamado Astronomy Quiz, que é um jogo de perguntas de astronomia, aprendo muito com esse jogo! Sigo um

Práxis Educativa, Ponta Grossa, v. 15, e2014790, p. 1-19, 2020 Disponível em: < https://www.revistas2.uepg.br/index.php/praxiseducativa> 
canal no YouTube, onde estudo meu inglês, que quero compartilhar com você, o nome é Small Advantages, muito bom! E o outro é um canal de pessoas que têm empresas famosas e contam como foi difícil e como conseguiram, é bem interessante o nome é Endeavor Brasil. (Diário da A, 2019).

Reflexos desse aperfeiçoamento do idioma inglês pela adolescente são vistos em suas composições musicais, todas em inglês, conforme menciona a mãe da adolescente:

[...] ela cria músicas, ela compõe músicas incriveis, assim, que tu vês que tem uma profundidade. [...]. Ai ela compõe o conteúdo superinteressante em inglês, e ela pega um instrumento musical que ela não sabe tocar, e ela já toca, e ela acha que tá ruim. (M, 2019, informação oral).

Nesse trajeto, é possível perceber, por meio da internet, a função de mediar, “[...] promover encantamento, mas também estranhamento, conversar e perguntar, ter dúvidas, inquietar-se e mover-se em diferentes direções" (URIARTE et al., 2016, p. 40).

\section{$\checkmark$ Aulas em espaços não formais}

O interesse que a adolescente tem pela arte, mencionado na entrevista e em seu Diário, possibilita-lhe percorrer espaços não formais de aprendizado, para que seu encontro com a música, com o circo e a pintura aconteça de maneira mais intensa, por meio de aulas e de cursos. "Realmente comecei a fazer aulas de música e circo, e talvez seja importante citar que eu mesma estou pagando com a minha mesada" (Diário da A, 2019). Em seu Diário, a adolescente registrou cursos de teatro e canto que realizou e apresentações artísticas de que participou: "Curso de teatro, com apresentação de uma peça, onde fui a diretora e também atriz" (Diário da A, 2019). "Curso de canto, onde fiz três apresentações" (Diário da A, 2019). Os locais para as aulas de circo, música e canto variam entre espaços particulares, escolas de música ou clubes. Já a "[...] aula de pintura em tela, em ateliê particular [...]”, conforme cita a adolescente (Diário de Campo, 2019).

A mediação cultural e a relação entre/com esses espaços educativos não formais podem contribuir para a formação estética e artística dos sujeitos, haja vista promoverem a interação, a produção artística, a diversidade e a dinamicidade metodológica das práticas (KUPIEC; NEITZEL; CARVALHO, 2016), pois esses lugares de aulas em espaços não formais tornam-se “[...] um lugar que recebe o outro e o coloca em correspondência com os sentires" (KUPIEC; NEITZEL; CARVALHO, 2016, p. 25). Desse modo, são espaços que colocam a adolescente em contato mais intenso com seus interesses ligados à arte.

\section{Considerações finais}

Diante do exposto, podemos afirmar que a rede que relaciona o unschooling e os percursos de mediação cultural, neste estudo de caso, é formada pelos seguintes elementos: interesses e liberdade; autonomia; rede de pessoas, mediadores; locais de exposição tais como museus e teatros; internet como mediadora; e aulas em espaços não formais. Então, tecemos a teia (Figura 3) para a mediação cultural neste percurso de unschooling e os elementos que a compõem: 
Figura 3 - Teia da mediação cultural no unschooling

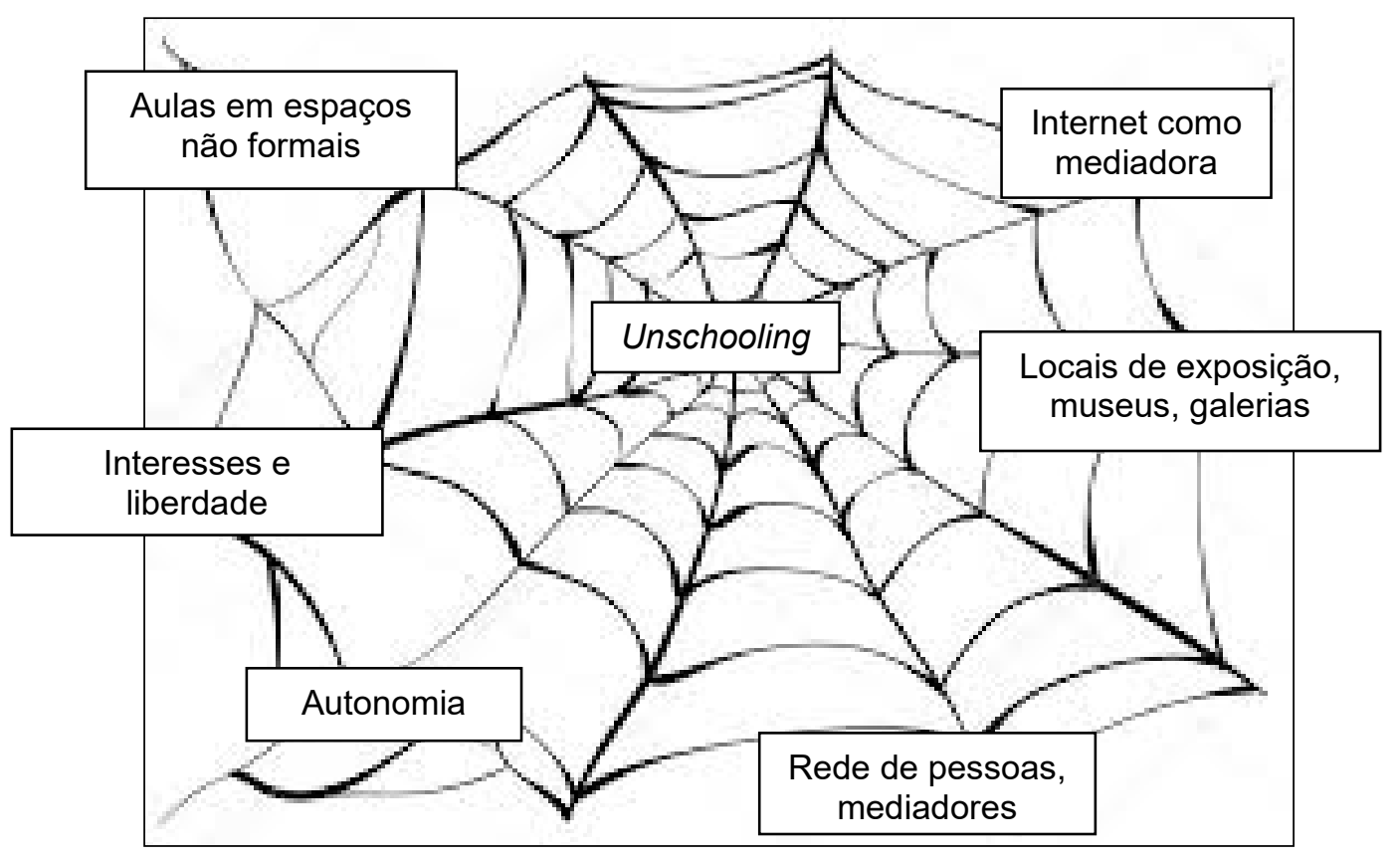

Fonte: Elaborada pelas autoras.

É possível perceber que as palavras e os conceitos se entrelaçam de tal sorte que não podem agir sós, mas somente amarrados uns aos outros, a exemplo de "rede de pessoas, mediadores" e de "seus interesses e liberdade".

Percebemos, durante a pesquisa, diversos momentos de tensão nesse percurso, mas não são o foco deste artigo. Contatamos que a dinâmica familiar mudou completamente com a escolha da prática do unschooling, bem como que outras relações se estabeleceram a partir dessa decisão e escolha familiar. Observamos que a rede de apoio a essas famílias é formada por outras famílias que, de alguma forma, também praticam processos de ensino fora da escola. Assim, criam redes de apoio que mobilizam e fortalecem o que realizam. Por vezes, a adolescente percebe que a escolha familiar a faz enfrentar outros desafios, pois estar fora de um "sistema" cria oportunidades, mas também embates, que precisam ser enfrentados.

Realizar uma pesquisa que tenha como objeto central a compreensão dos processos estéticos e artísticos no contexto de unschooling pode trazer reflexões e contribuições para a realidade do ensino de artes, tanto em espaços formais como não formais de educação. Nesse sentido, em relação à mediação cultural, à aproximação com a arte e à estética, essa família criou e cria oportunidades para a adolescente ter acesso à arte. Observamos que as condições objetivas são marcadas pelo capital cultural e econômico da família. Os pais têm formação acadêmica na área de educação, o que nos provoca a pensar que parte desse percurso tem relação com a compreensão da relevância dos bens culturais, históricos e artísticos por parte da própria família. Assim sendo, se na escola o habitus (BOURDIEU, 2004) é formado a partir dos professores, no uschooling, o babitus (BOURDIEU, 2004) forma-se a partir do que a família oferece?

Esses indicadores são apenas para nos fazer pensar e refletir sobre os desafios que estão por vir com as novas políticas educacionais vigentes no Brasil e com a complexidade característica da sociedade atual. 


\section{Referências}

ANED. Associação Nacional de Educação Domiciliar. ED no Brasil: dados sobre educação domiciliar no Brasil. ANED, [S. 1.], 2019. Disponível em: < https://www.aned.org.br/conheca/edno-brasil>. Acesso em: 21 ago. 2019.

BOGDAN, R.; BIKLEN, S. Investigação qualitativa em educação: uma introdução à teoria e aos métodos. Porto: Porto Editora, 1994.

BOURDIEU, P. Coisas ditas. Tradução Cássia R. da Silveira e Denise Moreno Pegorim. São Paulo: Brasiliense, 2004.

BRASIL. Supremo Tribunal Federal. STF nega recurso que pedia reconhecimento de direito a ensino domiciliar. Brasília: STF, 12 set. 2018. Disponível em: $<$ http://stf.jus.br/portal/cms/verNoticiaDetalhe.asp?idConteudo=389496>. Acesso em: 18 ago. 2019.

BRASIL, Projeto de Lei $\mathbf{N}^{\circ}$ 2.401, de 17 de abril 2019. Dispõe sobre o exercício do direito à educação domiciliar, altera a Lei no 8.069, de 13 de julho de 1990 - Estatuto da Criança e do Adolescente, e a Lei n ${ }^{\circ}$ 9.394, de 20 de dezembro de 1996, que estabelece as diretrizes e bases da educação nacional. Brasília: Câmara dos Deputados, [2019]. Disponível em: $<$ https://www.camara.leg.br/proposicoesWeb/ fichadetramitacao?idProposicao=2198615>.

Acesso em: 18 ago. 2019.

CASANOVA, L. V.; FERREIRA, V. S. Os discursos da Associação Nacional de Educação Domiciliar no Brasil. Práxis Educativa, Ponta Grossa, v. 15, p. 1-17, 2020. DOI: https://doi.org/10.5212/PraxEduc.v.15.14771.025

FARENGA, P. Blog John Holt GWS, [S. 1.], 2013a. Disponível em: <https://johnholtgws.squarespace.com/>. Acesso em: 11 jul. 2019.

FARENGA, P. Homeschooling and unschooling: resources. Blog John Holt GWS, [S. l.], 2013b. Disponível em: <https://www.johnholtgws.com/homeschooling-unschooling-resources>. Acesso em: 11 jul. 2019.

FLICK, U. Introdução à pesquisa qualitativa. Tradução Joice Elias Costa. 3. ed. Porto Alegre: Artmed, 2009.

GASKELL, G. Entrevistas individuais e grupais. In: BAUER, M. W.; GASKELL, G. (orgs.). Pesquisa qualitativa com texto, imagem e som: um manual prático. Petrópolis: Vozes, 2002. p. 64-136.

GONÇALVES, M. P. C. Práticas educacionais e processos de subjetivação em meio a propostas de desescolarização: tensões. 2016. 143 f. Dissertação (Mestrado em Psicologia) Universidade de São Paulo, São Paulo, 2016.

ILLICH, I. Sociedade sem escolas. Tradução Lúcia Mathilde Endlich Orth. Petrópolis: Vozes, 1985.

KUPIEC, A.; NEITZEL, A. de A.; CARVALHO, C. A mediação cultural e o processo de humanização do homem. In: NEITZEL, A. de A.; CARVALHO, C. (orgs.). Mediação cultural, formação de leitores e educação estética. Curitiba: CRV, 2016. p. 23-36. 
LORETI, G. Mamãe é a melhor professora!: uma etnografia junto a três famílias que educam suas crianças fora da escola. 2019. 205 f. Dissertação (Mestrado em Antropologia Social) Universidade Federal de São Carlos, São Carlos, 2019.

MARCONDES, N. A. V.; BRISOLA, E. M. A. Análise por triangulação de métodos: um referencial para pesquisas qualitativas. Revista Univap, São José dos Campos, v. 20, n. 35, p. 201 208, ago. 2014. DOI: http://dx.doi.org/10.18066/revunivap.v20i35.228.

MARTINS, M. C. Mediações culturais e contaminações estética. Revista Gearte, Porto Alegre, v. 1, n. 2, p. 248-264, ago. 2014. DOI: https://doi.org/10.22456/2357-9854.52575

MONRAT, L. Fluir: o devir da autopoiese. Florianópolis: Edição do Autor, 2018.

MONRAT, L. Informações sobre unschooling e livre aprendizagem. [mensagem pessoal] Mensagem recebida por helentche@gmail.com em 27 jun. 2019.

OLIVEIRA, M. C. P. de. Abrindo as janelas para o que tem fora dos muros da escola. In: MARTINS, M. C. (org.). Pensar juntos mediação cultural: [entre]laçando experiências e conceitos. São Paulo: Terracota, 2014. p. 99-108.

PESSOA, A. V. Práticas pedagógicas na educação domiciliar: um estudo de caso em AracajuSE. 2019. 123 f. Dissertação (Mestrado em Educação) - Universidade Federal de Sergipe, São Cristóvão, 2019.

SALGADO, G. N. Educação “alternativa”: do discurso à imagem. 2018. 297 f. Tese (Doutorado em Educação) - Universidade Federal de Santa Catarina, Florianópolis, 2018.

TOURAINE, A. Crítica da modernidade. Tradução Elia Ferreira Edel. 5. ed. Petrópolis: Vozes, 1994.

URIARTE, M. Z. et al. Mediação Cultural: função de mestre explicador ou ação de mestre emancipador? In: NEITZEL, A. de A.; CARVALHO, C. (Orgs.). Mediação Cultural, formação de leitores e educação estética. Curitiba: CRV, 2016. p. 37-51.

ZAPPELLINI, M. B.; FEUERSCHÜTTE, S. G. O uso da triangulação na pesquisa científica brasileira em administração. Administração: Ensino e Pesquisa, Rio de Janeiro, v. 16, n. 2, p. 241 273, 30 jun. 2015. DOI: https://doi.org/10.13058/raep.2015.v16n2.238

Recebido em 31/12/2019

Versão corrigida recebida em 02/04/2020

Aceito em 04/04/2020

Publicado online em 08/04/2020 